\title{
Generation of alkoxyalkynylketenes from a bicyclic precursor. Cycloaddition chemistry with alkynes and theoretical studies regarding the formation of five- versus six-membered ring products
}

\author{
Mario Fernández-Zertuche**a , Susana López-Cortina a , Ma Elena Meza-Aviñaa \\ Mario Ordóñez, ${ }^{a}$ and Alejandro Ramírez-Solís ${ }^{b}$ \\ ${ }^{a}$ Centro de Investigaciones Químicas, and ${ }^{b}$ Depto. de Física, Facultad de Ciencias, Universidad \\ Autónoma del Estado de Morelos, Av. Universidad 1001 \\ Col. Chamilpa, Cuernavaca, Mor. 62210 México \\ E-mail:mfz@ciq.uaem.mx
}

(received 29 Aug 03; accepted 05 Nov 03; published on the web 22 Nov 03)

\begin{abstract}
A bicyclic [2.2.2] octadiene framework in which the ethano bridge contains a carbonyl group, an alkynyl and a trimethylsiloxy or hydroxy group has been utilized to generate alkoxyalkynylketenes via a retro-Diels-Alder reaction under relatively mild conditions $\left(138{ }^{\circ} \mathrm{C}\right)$. This is an outstanding result since the retro-Diels-Alder reaction of [2.2.2]bicyclic compounds proceeds quantitatively but at unusually high temperatures $\left(>500^{\circ} \mathrm{C}\right)$. The ketenes generated undergo [2+2] cycloadditions to alkynes in a sequence of events that lead to the formation of five- or six-membered ring products. We show using quantum chemical calculations that formation of five- or six-membered rings in the overall process is a function of the substituents on the alkynes used to trap the ketenes.
\end{abstract}

Keywords: Bicyclic compounds, retro-Diels-Alder, alkynylketenes, [2+2] cycloadditions, density functional theory

\section{Introduction}

The reversion of the Diels-Alder reaction has received much attention during the past decade. ${ }^{1}$ The development of low temperature cycloreversions and especially of flash vacuum thermolysis, ${ }^{2}$ which avoids any chemical medium, has broadened the scope of this reaction to allow the generation of many reactive molecules. In this respect, the retro Diels-Alder reaction of ethanonaphthalenes ${ }^{3}$ and anthracenes ${ }^{4}$ has been used to synthesize numerous otherwise hardly accessible molecules. The ethano bridge can be eliminated thermally or photochemically and when the bridge contains a carbonyl group, the eliminated molecule is a ketene. However, the 
generation of ketenes by this method has received little attention and only a few examples detailing the generation of dimethylketene have been reported. ${ }^{5}$

Ketenes in which an alkynyl group is directly conjugated to a ketene moiety (alkynylketenes) constitute a rare class of cumulenes, the only reported general route to such cumulenes involves the thermolysis of 2,5-dialkynyl-3,6-diazido-1,4-benzoquinones in refluxing benzene to afford alkynylcyanoketenes ${ }^{6}$ and the thermally induced retro-Diels-Alder reaction of 9,10-dihydro9,10-dimethoxy-11-oxo-12-(phenylethynyl)-12-(trimethylsiloxy)-9,10-ethanoanthracene at 220 ${ }^{\circ} \mathrm{C} .{ }^{7}$ To this end, potentially attractive precursors to alkoxyalkynylketenes $\mathbf{2}$ are simpler bicyclic [2.2.2] octadienones $\mathbf{1}$ in which the ethano bridge is suitably functionalized with a carbonyl group, and an alkynyl and alkoxide substituents next to the carbonyl group, the thermally induced retro Diels-Alder cleavage of this bridge could generate the aforementioned ketenes preferentially at lower temperatures. (Scheme 1)

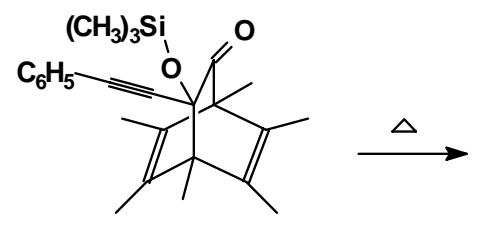

1

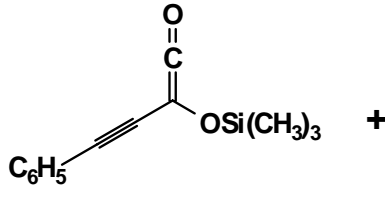

2

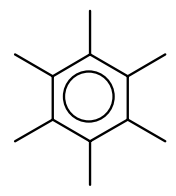

3

\section{Scheme 1}

We wish to report here our work on the thermally induced retro Diels-Alder fragmentation of the bicyclic [2.2.2] octadienones $\mathbf{4}$ and $\mathbf{5}$ in refluxing xylenes $\left(138{ }^{\circ} \mathrm{C}\right)$ to generate ketenes $\mathbf{2}$ and 14, along with the aromatic byproduct $\mathbf{6}$, their [2+2] cycloaddition chemistry toward alkynes and some quantum chemical calculations regarding the formation of five- and six- membered rings in the overall process.

\section{Results and Discussion}

A recent study described by Chung et $a{ }^{8},{ }^{8}$ observed an acceleration on the rate of such retroDiels-Alder fragmentations as a function of increased electron-donating ability of the substituents at the bridgehead positions of the [2.2.2]bicyclic frameworks. With this in mind, our approach for the generation of 2 centered on the compound 1,4-dimethoxy-5-phenyl-3(phenylethynyl)-3-hydroxy-bicyclo[2.2.2]octadiene-2-one 4 (Scheme 2), a compound prepared via an unusual $\mathrm{ZnCl}_{2}$ catalyzed rearrangement we reported in the literature ${ }^{9}$ with all the required structural features to generate $\mathbf{2}$ at readily accessible lab temperatures. The silylation of $\mathbf{4}$ was carried out at in THF at $-78{ }^{\circ} \mathrm{C}$, when it was treated with 1.1 equivalents of n-butyllithium for 5 
minutes, followed by addition of 2.5 equivalents of freshly distilled trimethylsilyl chloride, the bicyclic [2.2.2] octadienone 5 was obtained in $60 \%$ yield.

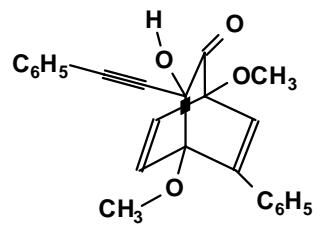

4

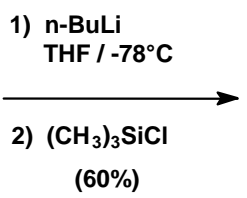

(60\%)

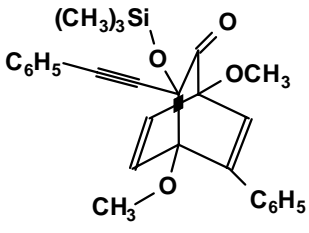

5
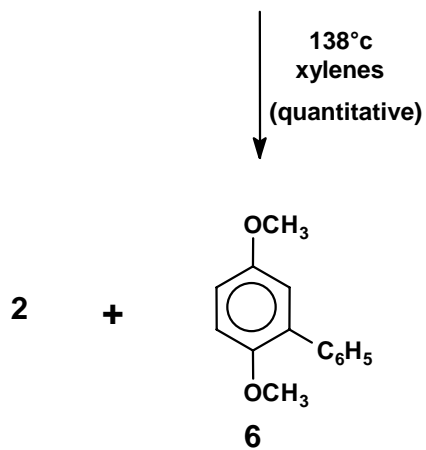

\section{Scheme 2}

In a successful experiment, it was found that thermally induced retro-Diels Alder reaction of 5 proceeds at $138{ }^{\circ} \mathrm{C}$ in xylenes to give the aromatic compound $\mathbf{6}$ in quantitative yield. The presence of the transient ketene 2 during the course of this reaction was evidenced by the development of a dark color in the reaction solution. This important finding then suggested that ketene $\mathbf{2}$ could be effectively trapped at this temperature if the thermolysis was carried out in the presence of ketenophiles.

The most synthetically useful reaction of ketenes is the [2+2] cycloaddition reaction to form a four-membered ring. Ketenes undergo this cycloaddition reaction with a variety of unsaturated compounds thus yielding a vast array of four-membered ring compounds.

A unique reaction sequence involving a series of pericyclic reactions has been accomplished when 5 was thermolyzed in the presence of alkynes (Table 1). (Trimethylsiloxy)(phenylethynyl)ketene 2 , generated in situ from 5, reacts with alkynes in a series of events that lead to the formation of 1,3-cyclopentenediones $\mathbf{7}$ or benzoquinones 8 in yields ranging from $37-55 \%$ (Table 1 ).

The formation of these products thus lends evidence for the generation of $\mathbf{2}$ from $\mathbf{5}$. The structures of these products were assigned based upon their spectral data. The infrared spectra of cyclopentenones 7a-c show sharp ketone bands around $1700 \mathrm{~cm}^{-1}$, typical of strained conjugated ketones such as these. Benzoquinones 8d-e absorb at $1650 \mathrm{~cm}^{-1}$. Moreover, the ${ }^{13} \mathrm{C}$ NMR of these compounds show the carbonyl peaks of cyclopentenones 7a-c in a more deshielded (190$195 \mathrm{ppm}$ ) region relative to those of benzoquinones $\mathbf{1 3}$ which normally appear in the 170-180 
ppm region. Further inspection of Table 1 discloses some other interesting features. For example, entries a-b lead exclusively to products containing a five-membered ring whereas entries d-e to a six-membered ring. In all these cases, only entry c gave a 4:1 ratio of five- versus six-membered ring products. The formation of all these products presents an interesting mechanistic problem for which there is precedent. That is, analogous products are observed when 4-phenylethynyl-4trimethylsiloxy (or hydroxy)-2,3-dimethoxycyclobutenone was thermolyzed at $138{ }^{\circ} \mathrm{C}$ in refluxing xylenes. ${ }^{10}$

Table 1. Thermolysis of 5 in the presence of alkynes

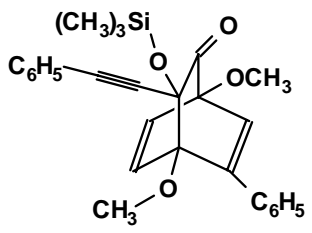

5

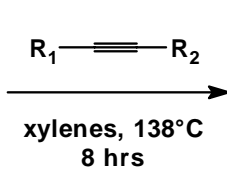

8 hrs

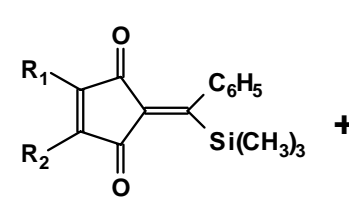

7a-c

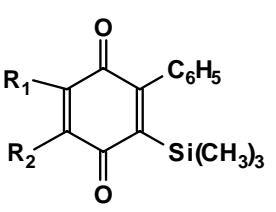

8c-e

\begin{tabular}{|ccccc|}
\hline & $\mathrm{R}_{1}$ & $\mathrm{R}_{2}$ & \% Yield 7 & \% Yield 8 \\
\hline a & $-\mathrm{C}_{6} \mathrm{H}_{5}$ & $-\mathrm{C}_{6} \mathrm{H}_{5}$ & 55 & -- \\
\hline b & $-\mathrm{C}_{2} \mathrm{H}_{5}$ & $-\mathrm{C}_{2} \mathrm{H}_{5}$ & 42 & -- \\
\hline c & $-\mathrm{CH}_{3}$ & $-\mathrm{C}_{6} \mathrm{H}_{5}$ & 48 & 12 \\
\hline d & $-\mathrm{CH}_{3}$ & $-\mathrm{OC}_{2} \mathrm{H}_{5}$ & -- & 45 \\
\hline e & $-\mathrm{H}$ & $-\mathrm{C}_{6} \mathrm{H}_{5}$ & & 37 \\
\hline
\end{tabular}

The products obtained in these reactions can be seen to arise from the sequence of reactions shown in Scheme 3. Alkynylketene 2, generated in situ from $\mathbf{5}$ combines with the ketenophilic alkynes in a regiospecific [2+2] cycloadditions to give the alkynylcyclobutenone $\mathbf{9}$. Under the thermal conditions of the reaction, $\mathbf{9}$ is not stable and undergoes a reversible four-electron electrocyclic ring opening to ketene $\mathbf{1 0}$ which is then subjected to a six-electron electrocyclization through pathways a or c to form either $\mathbf{1 1}$ or $\mathbf{1 2}$. Migration of the silyl group ${ }^{11}$ gives respectively $\mathbf{7}$ or $\mathbf{8}$. These sequence of events involve no less than four pericyclic reactions: a retro-Diels-Alder cleavage, a [2+2] cycloaddition, an electrocyclic ring opening and an electrocyclic ring closure in one single operation.

An important issue about the mechanistic pathway outlined in Scheme 3, which needs to be addressed is that about the influence of substituents $R_{1}$ and $R_{2}$ on ketene $\mathbf{1 0}$ in controlling fiveversus six- ring formation. It is postulated here that the product distribution observed in the overall reactions of ketene $\mathbf{2}$ with alkynes is a function of the repulsive effects exerted by $R_{1}$ and $\mathrm{R}_{2}$ within ketenes $\mathbf{1 0}$.

The trends observed in Table 1 suggest that bulkier groups favor the formation of a fivemembered ring and less sterically demanding groups a six-membered ring. In the light of these results, we decided to analyze the electrocyclization step of this synthetic sequence performing 
some quantum chemical calculations on ketenes 10a $\left(\mathrm{R}_{1}=\mathrm{R}_{2}=\mathrm{Ph}\right)$ and 10b $\left(\mathrm{R}_{1}=\mathrm{CH}_{3}, \mathrm{R}_{2}=\right.$ $\mathrm{OC}_{2} \mathrm{H}_{5}$ ) to determine any changes on their preferred conformation as function of substituents $\mathrm{R}_{1}$ or $\mathrm{R}_{2}$ that could favor the formation of either $\mathbf{7}$ or $\mathbf{8}$.
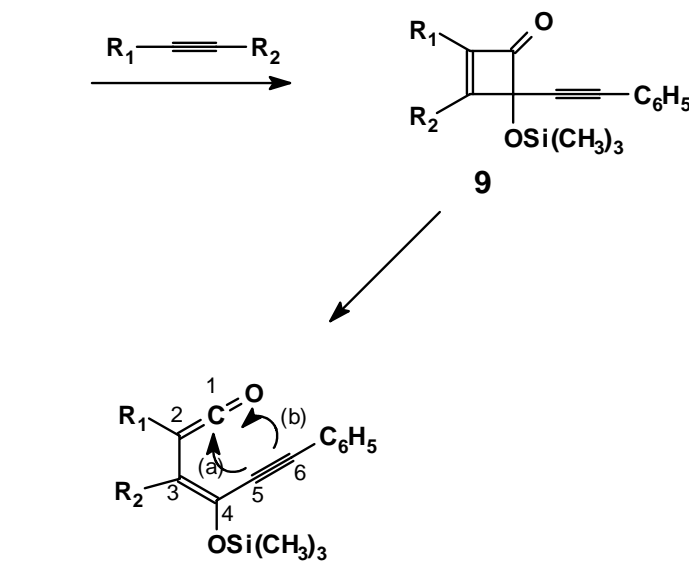

10

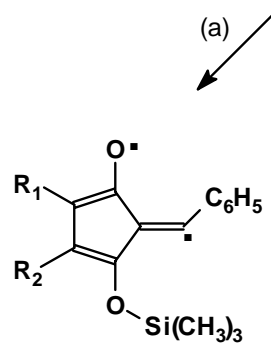

11

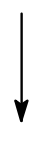

7

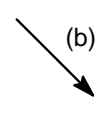<smiles>[R]c1c(OC)cc(-c2ccccc2)c([O-])c1[R]</smiles>

12

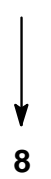

\section{Scheme 3}

In order to achieve our goal, we performed density functional theory (DFT) based calculations and full geometry optimizations using the standard 6-31G** basis of the Gaussian98 program ${ }^{12}$ on both structures 10a and 10b presented in Scheme 3. The hybrid B3LYP exchange and correlation functionals were used for these optimizations, and the stable structures were characterized as true minima in the potential energy surface by the absence of imaginary frequencies in the vibrational analysis.

When $\mathrm{R}_{1}=\mathrm{R}_{2}=\mathrm{Ph}$ (Figure 1), that is sufficiently large groups, a strong steric repulsion between the phenyl groups develops, inducing a loss of planarity on ketene 10a. As a consequence, the alkyne moiety is bent out and, in doing so, allows a better overlap between the orbitals at $\mathrm{C}_{1}$ and $\mathrm{C}_{5}$ leading to the formation of the five-membered ring. The dihedral angle that links the carbon atoms in the backbone is $58^{\circ}$ for $\mathrm{C}_{1}-\mathrm{C}_{2}-\mathrm{C}_{3}-\mathrm{C}_{4}$ thus reflecting the strong lack of planarity for this case. 


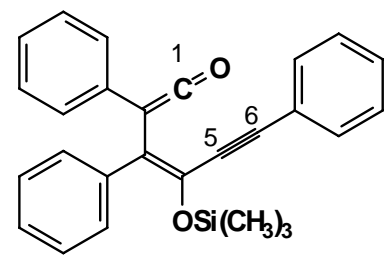

10a

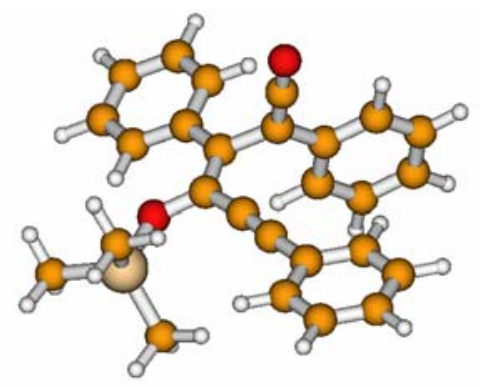

Figure 1. Structure and B3LYP/6-31G** optimized geometry of ketene 10a.

When $\mathrm{R}_{1}$ or $\mathrm{R}_{2}$ or both are small $\left(\mathrm{R}_{1}=\mathrm{CH}_{3}, \mathrm{R}_{2}=\mathrm{OC}_{2} \mathrm{H}_{5}\right.$, Figure 2), ketene 10b adopts a nearly planar configuration that allows a more efficient overlap between the orbitals at $\mathrm{C}_{1}$ and $\mathrm{C}_{6}$, facilitating the formation of a six-membered ring. For the small $\mathrm{R}_{1}$ or $\mathrm{R}_{2}$ substituents, the dihedral angle that links the carbon atoms in the backbone is only $19^{\circ}$ for $C_{1}-C_{2}-C_{3}-C_{4}$, which is much smaller than for the bulkier substituents, thus leading to the nearly flat configuration previously mentioned.

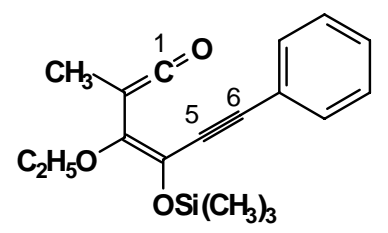

10b

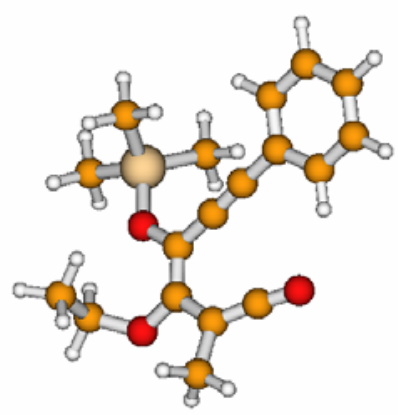

Figure 2. Structure and B3LYP/6-31G** optimized geometry of ketene $\mathbf{1 0 b}$.

Of course, combination of these effects is possible with middle-sized substituents leading to the formation of mixtures. This is the case of entry c (Table 1) where a 4:1 ratio of five- over sixmembered ring products is obtained. Obviously, additional studies will need to be done for a cleared understanding on the factors that control the product distribution of Table 1.

Another important aspect on the mechanism of this reaction is the nature of the intermediates obtained by the ring-closure of ketenes $\mathbf{1 0}$. Although the diradical character of the intermediates 11 and 12 obtained by ring closure of $\mathbf{1 0}$ has been suggested in the literature, ${ }^{13}$ we have demonstrated the allene character at least in the formation of the six-membered ring. ${ }^{14}$

Finally, regarding the ring opening of cyclobutenone $\mathbf{9}$, it appears from the results of Table 1 that these transformations are derived from a conrotatory ring opening of $\mathbf{9}$ in such a way that the trimethylsiloxy group rotates outward. ${ }^{15}$ Thus, the configuration of ketene $\mathbf{1 0}$ is such that their electrophilic site can interact with the proximal alkynyl group. This is in agreement with 
theoretical studies that conclude that the observed outward rotation of electron-donating groups can be rationalized on the basis of electronic rather than steric effects.

Another example of these pericyclic cascades is given in Scheme 4. Here, the hydroxybicyclo[2.2.2]octadienone $\mathbf{4}$ was directly thermolyzed in the presence of diphenylacetylene to form $\mathbf{1 3}$ in 34\% yield. This is an outstanding result since this product is derived from the intermediacy of the elusive hydroxyketene $\mathbf{1 4}$ via the sequence of reactions outlined in Scheme 3.

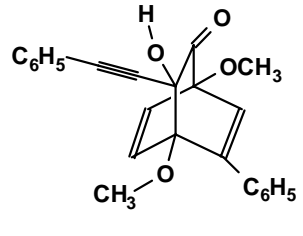

4

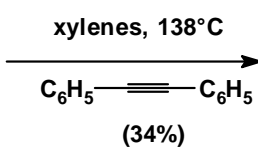

(34\%)

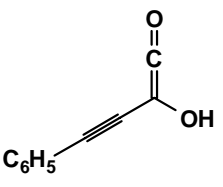

14

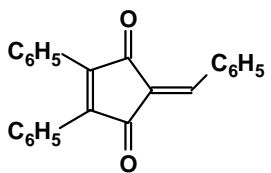

13

\section{Scheme 4}

\section{Conclusions}

The first examples of alkoxyalkynylketenes, (phenylethynyl)(trimethylsiloxy) 2 and (phenylethynyl)(hydroxyl)ketene $\mathbf{1 4}$ have been successfully generated by the retro-Diels-Alder fragmentation of bicycle [2.2.2] octadienone $\mathbf{5}$ and $\mathbf{4}$ in xylenes. The significance of these results are twofold. First, these alkynylketenes are members of a new class of ketenes and the pioneering work regarding their chemistry, particularly [2+2] cycloadditions, has been accomplished. The second noteworthy aspect of this work is the success met when these ketenes were generated from a bicyclic compound via a retro-Diels-Alder reaction that proceeds under relatively mild conditions $\left(138^{\circ} \mathrm{C}\right)$. Historically, the retro-Diels-Alder reaction of [2.2.2]bicyclic compounds has been reported to proceed at very high temperatures $\left(>500{ }^{\circ} \mathrm{C}\right)$. An important limitation to this approach, however, is the fact that the method cannot be extended to generate other examples of this type of ketenes. Therefore, a more general method must still be developed. 


\section{Experimental Section}

General Procedures. The reaction flasks and other glass equipment were heated in an oven at $130^{\circ} \mathrm{C}$ overnight and assembled in a stream of dry $\mathrm{N}_{2}$. Solvents were purified and dried according to standard procedures. Flash chromatography was performed with silica gel 60 (230400 mesh). Silica gel $F_{254}$ plates were used for TLC monitoring. Melting points were determined in a Büchi B-540 apparatus in open capillary tubes and are uncorrected. IR spectra were recorded on a Brucker vector 22 FT-IR. NMR spectra were recorded on an Inova Varian at 400 and 200 $\mathrm{MHz}$ for ${ }^{1} \mathrm{H}$ and 100 and $50 \mathrm{MHz}$ for ${ }^{13} \mathrm{C}$. The $J$ values are given in Hertz. Mass spectra were determined by using a medium-resolution Finnigan 4000 GC/MS quadrupole spectrometer interfaced to a Nova 312 data system. High-resolution mass spectra were obtained from a 7070EVG analytical organic mass spectrometer interfaced to a VG Analytical LTD 11/250 data system. Microanalyses were registered on a Elemental VARIO EL III instrument.

\section{1,4-Dimethoxy-5-phenyl-3-(phenylethynyl)-3-(trimethylsiloxy)-bicyclo [2.2.2]octadiene -2-} one (5). In a flame-dried $250 \mathrm{~mL}$ round bottomed flask, under argon, 0.70g (1.87 mmol) of 1,4dimethoxy-2-phenyl-7-phenyethynyl-7-hydroxybicyclo [2.2.2]octadiene-8-one $4^{9}$ was dissolved in $100 \mathrm{~mL}$ of dry THF. The solution was cooled to $-78^{\circ} \mathrm{C}$ and then $2.1 \mathrm{~mL}$ (2.06 mmol) of $\underline{\mathrm{n}}-$ butyllithium (0.95M in hexanes) was slowly added, the colorless solution at this point turned to a bright orange color. The solution was stirred at $-78{ }^{\circ} \mathrm{C}$ for 10 minutes and then quenched with $0.36 \mathrm{~mL}$ (2.82 mmole) of freshly distilled trimethylsilyl chloride. The mixture was allowed to warm to room temperature and stirred until it became colorless again. Removal of the solvent yielded a yellow oil and the desired product was separated by a flash column (silica-gel, hexanes/ethyl acetate 9:1) to give $0.50 \mathrm{~g}(60 \%)$ of a colorless oil. ${ }^{1} \mathrm{H}$ NMR 7.60-7.30 (m. 10H), 6.68 (q, J=3.69 Hz, 2H), 6.22 (d, J=0.62Hz, 1H), 3.71 (s, 3H), 3.22 (s, 3H), 0.25 (s, 9H). IR (cm $\left.{ }^{-1}\right) 2200$ (w), 1755(s), 1610 (w), 1500 (s), 1450 (s), 1352 (s), 1258 (s). MS 444 (EI), 445 (CI). Exact mass calculated for $\mathrm{C}_{27} \mathrm{H}_{28} \mathrm{O}_{4} \mathrm{Si}: 444.17567$. Found: 444.17539 .

1,4-Dimethoxy-2-phenylbenzene (6). A solution of $100 \mathrm{mg}(0.22 \mathrm{mmol})$ of 1,4-dimethoxy-5phenyl-3-(phenylethynyl)-3-(trimethylsiloxy)-bicyclo [2.2.2]octadiene-2-one $\mathbf{5}$ in $25 \mathrm{~mL}$ of xylenes was refluxed for 8 hours, time after which tlc analysis showed disappereance of the starting material. The solvent was removed and the product purified by a chromatographic preparative plate (silica-gel, hexanes/ ethyl acetate 7:3). Evaporation of the solvent afforded 41mg (86\%) of a colorless oil. ${ }^{1} \mathrm{H}$ NMR 7.6-7.2 (m, 5H), 6.9 (m, 3H), 3.79 (s, 3H), 3.74 (s, 3H). IR ( $\mathrm{cm}^{-1}$ ) 2975 (w), 1510 (s), 1495 (s), 1265 (s), 1240 (s), 1055 (s). MS 214 (EI), 215 (CI). Exact mass calculated for $\mathrm{C}_{14} \mathrm{H}_{14} \mathrm{O}_{2}: 214.09937$. Found: 214.09689

4,5-Diphenyl-2-[phenyl(trimethylsilyl)methylene]-4-cyclopentene- 1,3-dione (7a). A solution of $86 \mathrm{mg}(0.19 \mathrm{mmol})$ of 1,4-dimethoxy-5-phenyl-3-(phenylethynyl)-3-(trimethylsiloxy)-bicyclo [2.2.2] octadiene-2-one 5 in $25 \mathrm{~mL}$ of xylenes was refluxed under argon, in the presence of $37 \mathrm{mg}$ $(0.21 \mathrm{mmol})$ of diphenyl acetylene. After 8 hours under reflux, tlc analysis showed the reaction to be complete. The solution was cooled to room temperature and the solvent removed. The 
product was isolated by a preparative chomatrographic plate (silica-gel, hexanes/ethyl acetate 4:1) as a yellow oil which upon addition of diisopropyl ether afforded $0.043 \mathrm{~g}(55 \%)$ of yellow needles mp 196-197 ${ }^{\circ} \mathrm{C} .{ }^{1} \mathrm{H}$ NMR 7.45- 7.22 (m, 13H), 6.94 (d, J=6.0 Hz, 2H), 0.21 (s, 9H). ${ }^{13} \mathrm{C}$ NMR 193.3, 189.9, 170.8, 151.5, 142.1, 134.3, 130.4, 130.3-128.0, 126.5, 124.3, 116.8, 113.2, 112.7, 0.45. IR ( $\left.\mathrm{cm}^{-1}\right) 1730$ (w), 1700 (d), 1600 (w), 1490 (m), 1450 (m), 1360 (m), 1230 (s). MS 408 (EI), 409 (CI). Anal. Calcd. for $\mathrm{C}_{27} \mathrm{H}_{24} \mathrm{O}_{2} \mathrm{Si}$ : C, 79.37; H, 5.92. Found: C, 79.18; H, 5.65.

4,5-Diethyl-2-[phenyl(trimethylsilyl)methylene]-4-cyclopentene-1,3-dione (7b). A mixture of $0.13 \mathrm{~g}(0.29 \mathrm{mmol})$ of 1,4-dimethoxy-5-phenyl-3-(phenylethynyl)-3-(trimethylsiloxy)-bicyclo [2.2.2] octadiene-2-one 5 and $0.33 \mathrm{~mL}(2.9 \mathrm{mmol})$ of 3-hexyne in $20 \mathrm{~mL}$ of dry benzene was heated in a sealed tube at $138{ }^{\circ} \mathrm{C}$ for 8 hours. The tube was then allowed to cool to room temperature and the solvent evaporated. A preparative chromatographic plate (silica-gel, hexanes/ethyl acetate 4:1) afforded $0.038 \mathrm{~g}(42 \%)$ of the product as a yellow oil. ${ }^{1} \mathrm{H}$ NMR 7.47.25 (m, 3H), 6.88 (d, J=7.1Hz, 2H), 2.52 (q, J=7.6Hz, 2H), 2.39 (q, J=7.59Hz, 2H), 1.18 (t, $\mathrm{J}=7.54 \mathrm{~Hz}, 3 \mathrm{H}$ ), 1.06 (t, J=7.62 Hz, 3H), 0.45 (s, 9H). ${ }^{13} \mathrm{C}$ NMR 194.8, 191.6, 166.7, 159.3, 157.5, 142.1, 134.3, 127.9, 127.8, 126.4, 124.5, 17.3, 17.3, 13.0, 12.8, 0.3. IR $\left(\mathrm{cm}^{-1}\right) 2995$ (m), 1698 (s), 1692 (s), 1640 (m), 1470 (m), 1352 (s), 1090 (m). Exact mass calculated for $\mathrm{C}_{19} \mathrm{H}_{24} \mathrm{O}_{2} \mathrm{Si}: 312.15455$. Found: 312.15455 .

4-Methyl-5-phenyl-2-[phenyl(trimethylsilyl)methylene]-4-cyclopentene-1,3-dione (7c) and 2,5-Diphenyl-3-methyl-6-trimethylsilyl-2,5-cyclohexadiene-1,4-dione (8c). A solution of $0.13 \mathrm{~g}(0.35 \mathrm{mmol})$ of 1,4-dimethoxy-5-phenyl-3-(phenylethynyl)-3-(trimethylsiloxy)-bicyclo [2.2.2] octadiene-2-one 5 and $0.10 \mathrm{~mL}(0.70 \mathrm{mmol})$ of 1-phenyl-1-propyne in $25 \mathrm{~mL}$ of xylenes, was heated on the reflux for 8 hours. The mixture was allowed to cool to room temperature and the solvent distilled off under vacuum. Products $7 \mathbf{c}$ and $\mathbf{8 c}$, formed in a $4: 1$ ration, were isolated by a preparative plate (silica-gel, hexanes/ ethyl acetate $4: 1$ ) to give $42 \mathrm{mg}(48 \%)$ of $7 \mathrm{c}$ and $12 \mathrm{mg}$ (12\%) of 8c as yellow oils with an overall yield of 60\%. Compound 7c: ${ }^{1} \mathrm{H}$ NMR 7.7-7.4 (m, 10H), 2.21 (s, 3H), 0.25 (s, 9H). IR ( $\left.\mathrm{cm}^{-1}\right) 2975$ (w), 1735 (w), 1700 (s), 1495 (m), 1250 (s), 1230 (s). MS 346 (EI). Exact mass calculated for $\mathrm{C}_{22} \mathrm{H}_{22} \mathrm{O}_{2} \mathrm{Si}: 346.1389$. Found : 346.14000 . Compound 8c : ${ }^{1} \mathrm{H}$ NMR 7.35- 7.15 (m, 10H), 2.06 (s, 3H), 0.08 (s, 9H). IR (cm $\left.{ }^{-1}\right) 1660$ (s), 1650 (s), 1518 (m), 1325(m), 1270 (s). MS 346 (EI). Exact mass calculated for $\mathrm{C}_{22} \mathrm{H}_{22} \mathrm{O}_{2} \mathrm{Si}$ : 346.1389. Found: 346.1389.

2-Ethoxy-3-methyl-5-phenyl-6-trimethylsiloxy-2,5-cyclohexadiene-1,4-dione (8d). A mixture of $97 \mathrm{mg}(0.22 \mathrm{mmol})$ of 1,4-dimethoxy-5-phenyl-3-(phenylethynyl)-3-(trimethylsiloxy)-bicyclo [2.2.2] octadiene-2-one 5 and $0.22 \mathrm{~mL}(2.20 \mathrm{mmol})$ of ethoxy-1-propyne, in $20 \mathrm{~mL}$ dry benzene, was heated in a sealed tube at $138{ }^{\circ} \mathrm{C}$ for 8 hours. The tube was then cooled to room temperature and the solvent removed. Preparative plate (silica-gel, hexanes/ethyl acetate 7:3) afforded 30mg (45\%) of the product as a yellow oil. ${ }^{1} \mathrm{H}$ NMR 7.5-7.2 (m, 5H), 4.38 (q, J= 7.09Hz, $2 \mathrm{H}$ ), 0.08 (s, 9H). IR ( $\left.\mathrm{cm}^{-1}\right) 1650$ (s), 1580(m), 1450(m), 1285(s), 1280(s). MS 314 (EI). Exact mass calculated for : $\mathrm{C}_{18} \mathrm{H}_{22} \mathrm{O}_{3} \mathrm{Si}: 314.13381$. Found: 314.1314.

3,6-Diphenyl-2-trimethylsilyl-2,5-cyclohexadiene-1,4-one (8e). In a flame dried 50mL flask equipped with condenser, $0.124 \mathrm{~g}$ ( $0.28 \mathrm{mmol}$ ) of 1,4-dimethoxy-5-phenyl-3-(phenylethynyl)-3- 
(trimethylsiloxy)-bicyclo [2.2.2] ]octadiene-2-one $\mathbf{5}$ in $25 \mathrm{~mL}$ of xylenes was refluxed under argon in the presence of $0.062 \mathrm{~mL}(0.56 \mathrm{mmol})$ of phenylacetylene. The reaction was complete after 8 hours under reflux. The solvent was removed and the product isolated by a preparative plate (silica-gel, hexanes/ethyl acetate 7:3) which afforded 34mg (37\%) of a yellow oil. ${ }^{1} \mathrm{H}$ NMR 7.60-7.22 (m, 10H), 6.89 (s, 1H), 0.05 (s, 9H). IR (cm $\left.{ }^{-1}\right) 1652$ (s), 1620(m), 1496(s), 1360(s), 1285(s), 1060(s). MS 332 (EI). Exact mass calculated for: $\mathrm{C}_{21} \mathrm{H}_{20} \mathrm{O}_{2} \mathrm{Si}$ : 332.12325. Found: 332.1228

4,5-Diphenyl-2-(phenylmethylene)-4-cyclopentene-1,3-dione (13). A solution of $0.10 \mathrm{~g}(0.26$ $\mathrm{mmol}$ ) of 1,4-dimethoxy-5-phenyl-3-(phenylethynyl)-3-(hydroxy)-bicyclo [2.2.2]octadiene-2one (4) in $20 \mathrm{~mL}$ of xylenes was refluxed under argon in the presence of 52mg $(0.29 \mathrm{mmol})$ of diphenylacetylene. After 8 hours under reflux, the reaction was complete and the solvent evaporated. Preparative plate (silica-gel, hexanes/ethyl acetate 7:3) gave a yellow oil which crystallized upon addition of diisopropyl ether to afford $0.030 \mathrm{~g}$ (34\%) of the product as yellow crystals mp 159-160 ${ }^{\circ} \mathrm{C} .{ }^{1} \mathrm{H}$ NMR 8.40 (d, 2H, J = 3.0 Hz), 7.77 (s, 1H), 7.6-7.2 (m, $\left.12 \mathrm{H}\right) .{ }^{13} \mathrm{C}$ NMR 192.6, 191.25, 152.5, 148.8, 143.7, 133.9, 133.8, 133.1, 132.8, 130.6, 129.67-122.66, 76.94. IR ( $\left.\mathrm{cm}^{-1}\right)$ 1690(s), 1638 (s), 1610 (w), 1355 (m), 1158(s), 1125 (s). MS 336 (EI). Anal. Calcd for $\mathrm{C}_{24} \mathrm{H}_{16} \mathrm{O}_{2}$ : C, 85.69; H, 4.79. Found: C, 85.50; 4.49.

\section{Acknowledgments}

The authors wish to thank CONACyT for providing financial support for this work through grants 3112P-E9607 and 41657-9. ARS thanks support from CONACYT project number 34673E and through the FOMES2000 Project "Cómputo Científico" for unlimited CPU time on the IBM p690 32-processor parallel supercomputer at UAEM.

\section{References}

1. (a) Klunder, A.J.H.; Zhu, J.; Zwanenburg, B. Chem. Rev. 1999,99,1163. (b) Rickborn, B. Org. React. 1998, 53, 223. Rickborn, B. Org. React. 1998, 52, 1.

2. Wiersum, U. E. Recl. Trav. Chim. Pays-Bas. 1978, 317, 365.

3. (a) Oku, A.; Kakihana, T.; Hart, H. J. Am. Chem. Soc. 1967, 89, 4554. (b) Neukam, W.; Grimme, W. Tetrahedron Lett. 1978, 2201. (c) Papies, W.; Grimme, W. Tetrahedron Lett. 1980, 21, 2799.

4. (a) Knopp, S.; Ornaf, R. M.; Rodrígues, K. E. J. Am. Chem. Soc. 1983, 105, 5494. (b) Rajanbabu, T. V.; Eaton, D.F.; Fukunaga, T. J. Org. Chem. 1983, 48, 652. (c) Ripoll, J. L. Tetrahedron 1977, 33, 389. (d) Hoffmann, R. W.; Schultler, R. Chem. Ber. 1975, 108, 844. (e) Hart, H.; Dean, D. L.; Buchanan, D. N. J. Am. Chem. Soc. 1973, 95, 6294. (f) Strating, J.; Zwanenburg, B.; Wagenaar, A.; Udding, A. C. Tetrahedron Lett. 1969, 125. 
5. Hart, H.; Murray, R. K. Tetrahedron Lett. 1968, 4996

6. Nguyen, N. V.; Chow, K.; Moore, H. W. J. Org. Chem. 1987, 52, 1315.

7. Pollart, D. J.; Moore, H. W. J. Org. Chem. 1989, 54, 5444.

8. Chung, Y. S.; Duerr, B. F.; Nanjappan, P.; Czarnik, A. W. J. Org. Chem. 1988, 53, 1334.

9. Fernández, M.; Chang, S.; Ziller, J.; Doedens, R. J. ; Moore, H. W. J. Org. Chem. 1989, 54, 1379.

10. (a) Moore, H. W.; Yerxa, B. R. Adv. Strain. Org. Chem. 1995, 4, 81. (b) Moore, H. W.; Yerxa, B. R. Chemtracts 1992, 5, 273. (c) Moore, H. W.; Decker, O. H. W. Chem. Revs. 1986, 86, 821. (d) Liebeskind, L. S. Tetrahedron 1989, 45, 3053.

11. (a) Mora, J.; Costa, A. Tetrahedron Lett. 1984, 3493. (b) Yamamoto, Y.; Muruyama, K.; Matsumoto, K. Organometallics 1984, 3, 1583.(c) Anderson, G.; Cameron, D. W.; Feutrill, G. I.; Read, R.W. Tetrahedron Lett. 1981, 4347.

12. Gaussian 98, Revision A.11.3, Frisch, M. J.; Trucks, G. W.; Schlegel, H. B.; Scuseria, G. E.; Robb, M. A.; Cheeseman, J. R.; Zakrzewski, V. G.; Montgomery Jr., J. A.; Stratmann, R. E.; Burant, J. C.; Dapprich, S.; Millam, J. M.; Daniels, A. D.; Kudin, K. N.; Strain, M. C.; Farkas, O.; Tomasi, J.; Barone, V.; Cossi, M.; Cammi, R.; Mennucci, B.; Pomelli, C.; Adamo, C.; Clifford, S.; Ochterski, J.; Petersson, G. A.; Ayala, P. Y.; Cui, Q.; Morokuma, K.; Rega, N.; Salvador, P.; Dannenberg, J. J.; Malick, D. K.; Rabuck, A. D.; Raghavachari, K.; Foresman, J. B.; Cioslowski, J.; Ortiz, J. V.; Baboul, A. G.; Stefanov, B. B.; Liu, G.; Liashenko, A.; Piskorz, P.; Komaromi, I.; Gomperts, R.; Martin, R. L.; Fox, D. J.; Keith, T.; Al-Laham, M. A.; Peng, C. Y.; Nanayakkara, A.; Challacombe, M.; Gill, P. M. W.; Johnson, B.;Chen, W.; Wong, M. W.; Andres, J. L.; Gonzalez, C.; Head-Gordon,M.; Replogle, E. S.; Pople, J. A. Gaussian, Inc., Pittsburgh PA, 2002.

13. (a) Moore, H. W.; Xiang, Y. J. Org. Chem. 1996, 61, 9168. (b) Xiang, Y.; Xia, H.; Moore, H. W. J. Org. Chem. 1995, 60, 6460.

14. (a) Fernández-Zertuche, M.; Ramírez-Solís, A.; Hernández-R.; Ordóñez, M. Rev. Soc. Quím. Méx. 2002,46, 136. (b) Fernández-Zertuche, M.; Hernández-Lamoneda, R.; Ramírez-Solís, A. J. Org. Chem. 2000, 65, 5207.

15. Houk, K. N.; Spellmeyer, D. C.; Jefford, C. W.; Rinbault, C. G.; Wang, Y.; Miller, R. D. J. Org. Chem. 1988, 53, 2125. 